\title{
Modeling Surface Runoff and Evapotranspiration using SWAT and BEACH for a Tropical Watershed in North Vietnam, Compared to MODIS Products
}

\author{
Hong Quang Nguyen and Martin Kappas
}

Geographisches Institut, Abteilung Kartographie, GIS und Fernerkundung, Goldschmidtstr. 5, 37077 Göttingen, Germany

Publication Date: 17 November 2015

Article Link: $\underline{\text { http://technical.cloud-journals.com/index.php/IJARSG/article/view/Tech-493 }}$

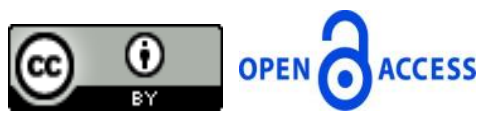

Copyright (c) 2015 Hong Quang Nguyen and Martin Kappas. This is an open access article distributed under the Creative Commons Attribution License, which permits unrestricted use, distribution, and reproduction in any medium, provided the original work is properly cited.

\begin{abstract}
Accurate estimation of surface runoff $(\mathrm{Q})$ and evapotranspiration (ET) is a challenging task but an important research topic because both $Q$ and ET play vital roles in the study of the hydrological cycle, of climate change, water resources, flood management and so on. In this paper we will present the modeling method to estimate the daily $Q$ and ET for a medium-sized watershed in the tropical region of the North of Vietnam using the Soil and Water Assessment Tool (SWAT) and Bridging Event and Continuous Hydrological $(B E A C H)$ models. The models were calibrated and validated for the river discharge for SWAT and evaporation (E) for BEACH in a 12 year period from 2001 to 2012. The simulated ETs by the models were compared with the satellite-based ET of MODIS products. Our simulation results show that the SWAT and $\mathrm{BEACH}$ models are capable of satisfactorily reproducing (with the NSE > 0.62 and $R^{2}>0.78$ ) the stream-gauged river discharge and the observed $E$, respectively. Daily ET varied from 0.3 to $14 \mathrm{~mm}_{\text {day }}{ }^{-1}$ and was highest from May to August and lowest from December to March. Although the monthly and yearly MODIS ETs were slightly higher than those of SWAT and BEACH, a strong relationship between them was found with a standard deviation ranging from three to $40 \mathrm{~mm}$. A light decrease of ET values in the 12 years can be seen in the result analyses; however a longer simulation time might be needed to ensure this trend.
\end{abstract}

Keywords Modeling Surface Runoff and Evapotranspiration; Nam Kim Watershed; Remote Sensing; GIS

\section{Introduction}

Currently, there has been growing interest in hydrological connectivity processes [1] such as surface runoff $(Q)$ and evapotranspiration (ET) [2-5]. Both these two processes are significant components in the water balance circle and linked to numerous environmental problems, for example excessive rainfall runoff causes soil erosion and water pollution [6, 7] land degradation [8], flooding [9, 10] etc. and changing ET might be the result of changes in weather [11], particularly in surface soil moisture and temperature [12,13] and land cover changes [4]. Surface runoff is defined as that part of the rainfall which is not observed by soil infiltration and which flows overland called overland-flow flowing 
in streams to the sea, all of which is dependent on the amount of rainfall, rainfall intensity and infiltration capacity [14]. The evapotranspiration is considered as the total water loss to the atmosphere [15] by evaporation both from the vegetative and non-vegetative surfaces and transpiration from plants $[11,16]$. Since the in situ measurements of surface runoff and ET for large areas are time consuming, costly and extremely difficult [3], indirect estimations of $Q$ and ET using the modeling approach and satellite-based products are necessary [17], particularly for sparse data-available areas such as in northern Vietnam.

Although many studies have been conducted using the modeling method at watershed scale for estimating $Q$, to name some of them [18-21] employing the SWAT, KINEROS2 and the HBV and VIC models, little attention has been paid to tropical regions using the SWAT model such as $[22,23]$ and for regions of Vietnam [24]. Similarly with studies on surface runoff, there is a large amount of literature available on research into ET including direct or in situ measurement $[25,26]$ and indirect methods (referring to modeling $[3,16]$ and using satellite technology [27, 28]), from watershed/catchment scales $[29,30]$ to the global scale [31-33] and others. Surprisingly, despite many scientific works having been conducted on ET elsewhere in the world as mentioned above, few or even no previous studies on that topic were found for the case study in Yen Bai province or in North Vietnam.

As mentioned at the very beginning, the importance of surface runoff and ET information and the lack of $Q$ and $E T$ literature on the study region have motivated the study objective of modeling and estimating that information. In addition, data scarcity has been reduced thanks to more ground-based hydrologic and meteorological stations being established in the region (for model calibration and validation) and in addition satellite data (MODIS, Landsat etc.) have become more available to make up for the lack of temporal and spatial data in ungauged regions [34] and be used for model validation [35] as well. The interesting point is that both large-scale in situ $Q$ and ET measurements are difficult, expensive and time consuming [13] but the modelling approach could be appropriate to deal with this challenge. Finally, the study results might be helpful for research into other fields such as $Q$ information for flood, ground/surface water management and ET for cropping irrigation, drought detection and management etc., particularly rapid change in climate, water and the increasing population have all become a great concern both for the environment and society [31].

In summary five main outcomes of expertise could be identified to cope with this study topic: (i) calibrating and validating daily river discharge and evaporation for the SWAT and BEACH model respectively, (ii) estimating daily ET by the two models, (iii) comparing SWAT, BEACH discharge and with observed data, (iv) comparing monthly ETs and analyzing their trend in the 2001-2012 period and, (v) mapping SWAT and MODIS annual accumulative ET. Our results elucidate the abilities of the two models to produce surface runoff and evaporation closely to field measured data, the strong relationships between SWAT, BEACH and MODIS ET and a slightly decreasing trend of ET in the simulating time.

\section{Study Site}

The study watershed is Nam Kim located in western Yen Bai province (Figure 1) has its center coordinate as $104^{\circ} 07^{\prime} 51.3^{\prime \prime} \mathrm{E}$ and $21^{\circ} 49^{\prime} 10.7^{\prime \prime} \mathrm{N}$. The mean elevation is 1571 meters above sea level and the area of the watershed is about $268 \mathrm{~km}^{2}$. The main land use land covers (LULC) are forest, agricultural (rice) and shrub lands with contributions of 40,33 and $23 \%$ of the watershed area respectively. The yearly mean air temperature varies from 20 to $24^{\circ} \mathrm{C}$ [36] and annual mean precipitation is $1695 \mathrm{~mm}$ (2001-2012 statistic from the rain gauge presented on the map). The dominant soils are Humic Ferralsols, Humic Acrisols and Humic Alisols and the cropping system is mainly rice and cassava harvested twice a year in May and October. There are three gauges established for measurements of rainfall, discharge and other meteorological data. 


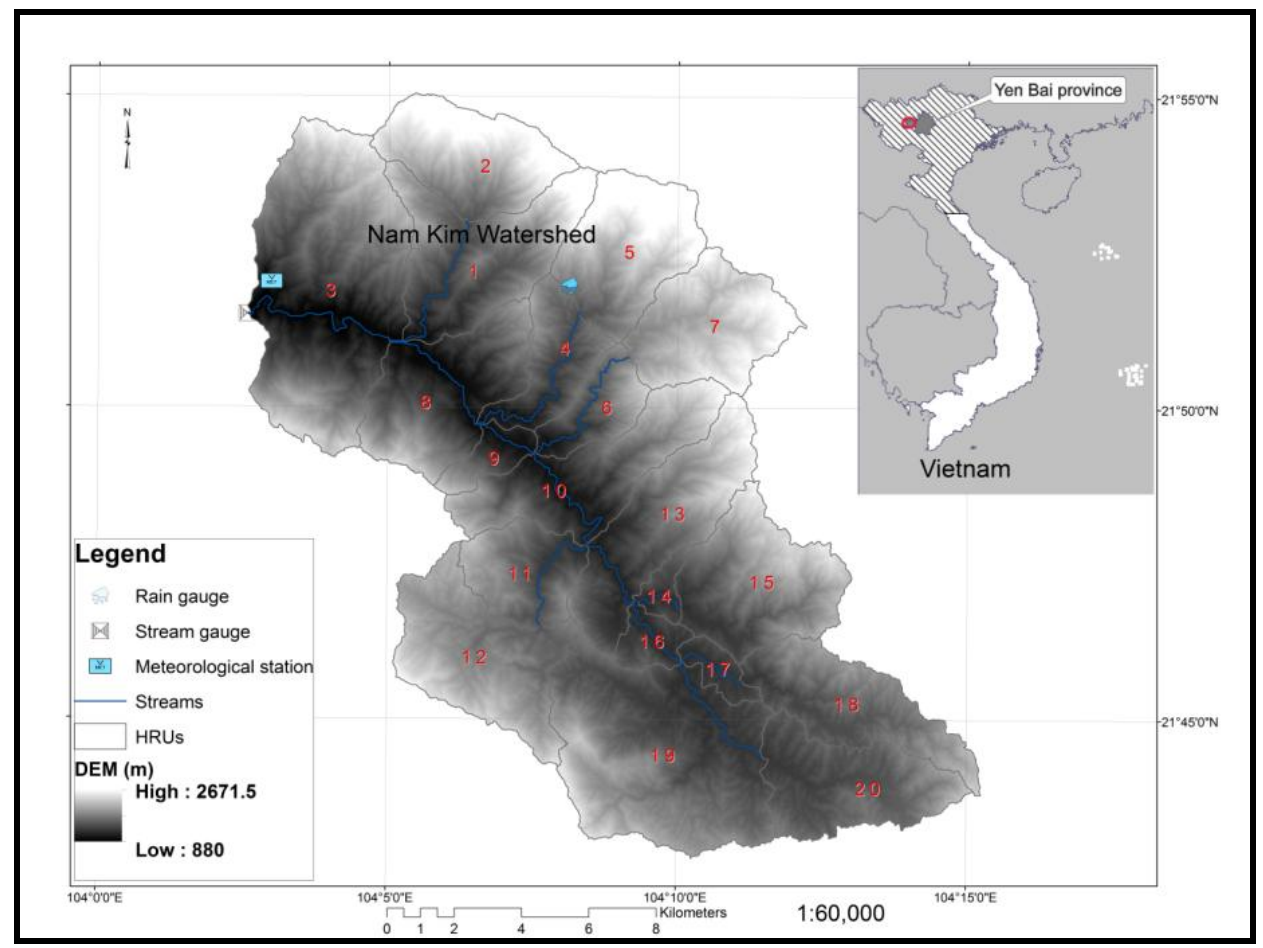

Figure 1: Map of Site Study and Stations for Data Collection

\section{Methods and Materials}

\subsection{The Soil and Water Assessment Tool (SWAT)}

SWAT is a physically based, continuous model and is computationally efficient, enabling users to study long-term impacts and is a long-term yield model [37]. The model simulates surface runoff volumes and peak runoff rates for each hydrologic response unit (HRU) using a modification of the SCS curve number method [38] or the Green \& Ampt infiltration method [39]. The evaporation from soils and plants are computed separately by the method described in [40]. Wherein, the potential evapotranspiration (PET) is the ET rate of a large area completely and uniformly covered with growing vegetation and an unlimited supply of soil water. In addition, the micro-climatic processes such as advection or heat-storage should not have effects on PET. The model uses Hargreaves [41], PriestleyTaylor [42] and Penman-Monteith [43] approaches for the estimation of PET.

\subsection{The Bridging Event and Continuous Hydrological (BEACH)}

The BEACH is a simple two-layer soil water balance model developed by Sheikh et al. [44] using freely available GIS and programming language, PCRaster. It is a spatially distributed daily basic hydrological model and has the ability to predict antecedent soil moisture, actual E and ET as its primary objective. The model also estimates the infiltration and runoff using either the Bucket or CN approach (for more details see Sheikh et al., 2009). Although the BEACH model offers two options of calculating runoff, the study results of [44] showed that the $C N$ approach performed better than the Bucket. That is reason for selecting the $\mathrm{CN}$ approach for simulating $\mathrm{Q}$ by the $\mathrm{BEACH}$ in this study.

In this model, the ET is separated into evaporation and transpiration and calculated based on the Penman-Monteith (FAO56) method [45]. Based on an assumption of a hypothetical grass cover with an assumed height of $0.12 \mathrm{~m}$, a surface resistance of $70 \mathrm{sm}^{-1}$ and an albedo of 0.23 , the FAO56 computes a reference evapotranspiration rate $\left(E T_{0}\right)$. The PET of the other surface is calculated by multiplying the $E T_{0}$ with a crop-specific coefficient $\left(K_{c}\right)$. 
The BEACH was developed for just one year (2004) hydrologic assessments, but for this study objective of long-term hydrological modeling (12 years) we recoded the code and made the model adapt to the requirement with an assumption that the crop harvesting seasons have not changed in the computational time.

\subsection{MODIS Evapotranspiration}

We used the MODIS ET of the improved algorithm [32] from the old algorithm [31] calculated as the sum of the $E$ from moist soil, the transpiration from vegetation during the daytime, intercepted canopy precipitation and $\mathrm{ET}$ in the nighttime. Some other improvements are the vegetation cover fraction $\left(F_{c}\right)$, the soil heat flux $(G)$, the wet surface fraction $\left(F_{\text {wet }}\right)$, evaporation from the wet canopy surface $\left(E_{\text {wet } \_} C\right)$, plant transpiration ( $\left.E_{\text {trans }}\right)$ etc. (more details see Mu et al. [32]).

The total daily ET is calculated as in following relation:

$$
\lambda E=\lambda E_{\text {wet } c}+\lambda E_{\text {trans }}+\lambda E_{\text {sorl }}
$$

Where $\lambda E_{\text {Sorz }}$ is the actual daily soil evaporation.

The monthly ET is summarized from daily ETs.

\subsection{SWAT Input}

SWAT requires four groups of input data including topography, LULC, soils and climatic data.

$>$ The topographic dataset commonly used is a Digital Elevation Model (DEM) which is employed to generate drainage network, flow directions, flow accumulation etc. for the topographical model's parameterization. We used a Triangular Irregular Network (TIN) extracted from Yen Bai geodatabase (provided by the Vietnam Resources and Environment Corporation, Hanoi Vietnam) for generating the $30 \times 30$ m DEM for the study area (Figure 1).

$>$ The Land use land cover (LULC) map (Figure 2) of nine classes (including cloud) was produced from Landsat scenes acquired in 2009 with $30 \times 30 \mathrm{~m}$ spatial resolution, seven bands of reflections. The map was classified using the supervised method in ENVI 4.7 software. The ground truth data was derived from the Yen Bai geodatabase. The accuracy of the classification was examined by calculating the user, producer accuracy and Kappa statistics for categorized classes (Table 1). The data shown within the table indicates the precision of the classification is at a good level with an overall accuracy of $78.6 \%$ and the Kappa coefficient of 0.73 . 


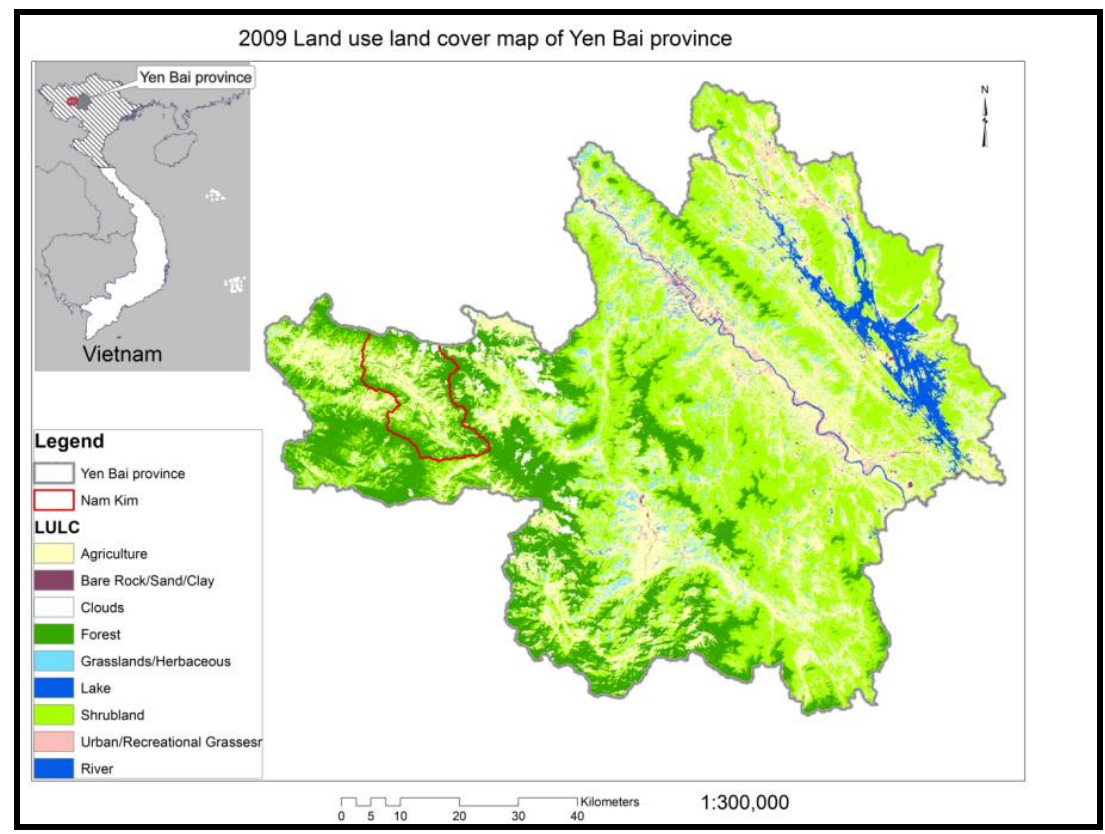

Figure 2: Landsat LULC Map of Yen Bai in 2009

Table 1: LULC Classification Accuracy Assessment

\begin{tabular}{cccccccccccc}
\hline $\begin{array}{c}\text { LULC } \\
\text { (Year) }\end{array}$ & $\begin{array}{c}\text { P/U } \\
(\%)\end{array}$ & Forest & Lake & River & Urban & Agriculture & Shrubland & Grassland & Barren & $\begin{array}{c}\text { O } \\
(\%)\end{array}$ & Kappa \\
\hline \multirow{2}{*}{2009} & $\mathrm{P}$ & 86.2 & 88.8 & 76.3 & 72.3 & 73.4 & 73.8 & 64.0 & 74.7 & \multirow{2}{*}{76.8} & 0.73 \\
\cline { 2 - 31 } & $\mathrm{U}$ & 86.5 & 82.7 & 74.7 & 75.2 & 68.8 & 73.1 & 73.3 & 78.7 & \\
\hline
\end{tabular}

$\mathrm{P}=$ Producer accuracy, $\mathrm{U}=$ User accuracy, $\mathrm{O}=$ Overall accuracy, and Kappa is the kappa statistic or kappa coefficient.

> Various physical and hydrological properties of soils are required by the model such as texture, hydraulic conductivity, bank density etc. Distribution of the soils was derived from a digital soil map of Yen Bai province produced in 1996 with six major soil groupings of fluvisols, calcisols, ferralsols, alisols, acrisols and gleysols.

> Climatic data required by the model includes daily rainfall, minimum and maximum temperature, wind speed, relative humidity, solar radiation and dew point temperature. This data can be read from measured data set or generated by a weather generator algorithm. We collected this data from the gauges (Figure 1) recorded from $1^{\text {st }}$ January 2011 to $31^{\text {st }}$ December 2012.

\subsection{BEACH Inputs}

Similar to SWAT, BEACH requires four main groups of input data: (i) topography, (ii) lands use, (iii) soil physical properties and (iv) climatic data. For the land use information, we need extra crop-specific information that could be obtained from literature of FAO paper no. 56 [45]. The overview of input for BEACH was indicated in the Table 2.

Table 2: Input Requirements of BEACH

\begin{tabular}{ccccc}
\hline Type & Data Resolution & Input Variables and Parameters & Unit & Source \\
\hline Topography & Constant & Slope map & $\mathrm{m} \mathrm{m}^{-1}$ & DEM \\
\hline & Constant & Drainage direction & - & DEM \\
\hline Constant & Wetness index $(W)$ & - & DEM \\
\hline
\end{tabular}




\begin{tabular}{|c|c|c|c|c|}
\hline Land use & Seasonally & Land use map & - & Satellite \\
\hline & Constant & Maximum leaf area index $\left(L A I_{\max }\right)$ & $m^{2} m^{-2}$ & Literature \\
\hline & Constant & Maximum crop height $\left(H_{\max }\right)$ & $\mathrm{m}$ & Literature (FAO56) \\
\hline & Constant & Maximum crop depth $\left(R D_{\max }\right)$ & $\mathrm{m}$ & Literature (FAO56) \\
\hline & Constant & Light use efficiency $(\mu)$ & - & Literature \\
\hline & Constant & Sowing and harvesting date & - & Literature \\
\hline & Constant & Growing stages & - & Literature (FAO56) \\
\hline & Constant & Basel crop coefficient $\left(K_{c b}\right)$ & - & Literature (FAO56) \\
\hline & Constant & Water stress sensitivity $(p)$ & - & Literature (FAO56) \\
\hline \multirow[t]{7}{*}{ Soil } & Constant & Yen Bai soil map & - & Database, field survey \\
\hline & For each layer & Layer depth $(D)$ & $\mathrm{m}$ & Soil map \\
\hline & Constant & Soil evaporation depth $\left(D_{e}\right)$ & $\mathrm{m}$ & User specified \\
\hline & For each layer & Subsurface flow coefficient $(c)$ & $d^{-1}$ & User specified \\
\hline & For each layer & Drainage coefficient $(T)$ & - & User specified \\
\hline & For each layer & Soil moisture at saturation $\left(\Theta_{\text {sat }}\right)$ & $\mathrm{m}^{3} \mathrm{~m}^{-3}$ & Literature \\
\hline & For each layer & Saturated hydraulic conductivity $\left(K_{\text {sat }}\right)$ & $\mathrm{m} \mathrm{d}^{-1}$ & Soil map, literature \\
\hline \multirow[t]{4}{*}{ Climate } & Daily & Reference evapotranspiration $\left(E T_{0}\right)$ & $\mathrm{m}$ & Weather station \\
\hline & Daily & Minimum relative humidity $\left(R H_{\min }\right)$ & $\%$ & Weather station \\
\hline & Daily & Wind speed $\left(U_{2}\right)$ & $\mathrm{m} \mathrm{s}^{-1}$ & Weather station \\
\hline & Daily & Precipitation $(P)$ & $\mathrm{m}$ & Weather station \\
\hline
\end{tabular}

\subsection{Model Calibration, Validation and Simulation}

> SWAT: Before model calibration, the watershed was modelled by dividing it into 20 HRUs (Figure 1) and parameterized with the inputs of topography, LULC and soils. The parameters were summarized in Table 3. Climatic parameterization was separately implemented and written to climatic datasets.

Table 3: SWAT Parameters for Nam Kim Watershed

\begin{tabular}{cccccccc}
\hline HRUs & $\begin{array}{c}\text { Area } \\
\left(\mathbf{k m}^{2}\right)\end{array}$ & $\begin{array}{c}\text { MeanElev } \\
(\mathbf{m})\end{array}$ & $\begin{array}{c}\text { AvgSlope } \\
\left(\mathbf{m ~ m}^{-1}\right)\end{array}$ & $\begin{array}{c}\text { MaxFlowLen } \\
(\mathbf{m})\end{array}$ & Main Soils & CN & Cover \\
\hline 1 & 17 & 1573 & 0.65 & 10522 & Humic Ferralsols & 47.4 & 46.4 \\
\hline 2 & 14 & 2026 & 0.57 & 5909 & Humic Alisols & 37.0 & 46.2 \\
\hline 3 & 35 & 1468 & 0.59 & 11203 & Humic Acrisols & 47.2 & 47.7 \\
\hline 4 & 8 & 1360 & 0.63 & 9076 & Humic Ferralsols & 50.6 & 44.6 \\
\hline 5 & 14 & 2008 & 0.61 & 7509 & Humic Alisols & 34.7 & 36.4 \\
\hline 6 & 6 & 1447 & 0.67 & 6766 & Humic Acrisols & 47.6 & 49.0 \\
\hline 7 & 14 & 1988 & 0.57 & 7979 & Humic Alisols & 43.1 & 65.0 \\
\hline 8 & 16 & 1343 & 0.56 & 7364 & Humic Ferralsols & 49.1 & 48.5 \\
\hline 9 & 3 & 1300 & 0.51 & 3233 & Humic Ferralsols & 49.7 & 52.8 \\
\hline 10 & 16 & 1484 & 0.58 & 10179 & Humic Ferralsols & 48.8 & 45.8 \\
\hline 11 & 9 & 1484 & 0.54 & 8726 & Humic Ferralsols & 49.5 & 40.6 \\
\hline 12 & 17 & 1717 & 0.53 & 6295 & Humic Ferralsols & 46.8 & 52.9 \\
\hline 13 & 16 & 1561 & 0.56 & 9042 & Humic Alisols & 47.7 & 47.1 \\
\hline 14 & 2 & 1260 & 0.49 & 3970 & Humic Ferralsols & 51.9 & 41.2 \\
\hline 15 & 16 & 1626 & 0.58 & 8837 & Humic Ferralsols & 47.6 & 50.0 \\
\hline 16 & 3 & 1232 & 0.52 & 3649 & Humic Ferralsols & 49.1 & 50.3 \\
\hline 17 & 2 & 1219 & 0.43 & 3752 & Humic Ferralsols & 50.0 & 45.2 \\
\hline 18 & 13 & 1506 & 0.57 & 11914 & Humic Ferralsols & 46.1 & 61.9 \\
\hline 19 & 31 & 1469 & 0.51 & 10366 & Humic Ferralsols & 47.6 & 54.6 \\
\hline 20 & 14 & 1412 & 0.51 & 8403 & Humic Ferralsols & 46.9 & 55.9 \\
\hline
\end{tabular}


MeanElve is average elevation, AvgSlope means average slope, MaxFlowLen is Maximum flow length, CN indicates area-weighted curve number based on soil type and land cover, and Cover is fraction of surface covered by intercepting cover.

In the model calibration stage, the $\mathrm{CN}$, infiltration and base flow recession parameter were adjusted to generate the estimated discharge close to observed discharge measured from 2001 to 2005. The model validation was done with observed discharge for a period of seven years from 2006 to 2012 .

D BEACH: The model was set up with the four crops of forest, shrub, rice (agriculture) and grass and calibrated with four-year measured E from 2001 to 2004. The calibrated model's input variables and parameters were tabularized in Table 4. As the observed $E$ is the point measurement and based on the LULC map, we made average estimated $E$ of the surrounding land use (shrub and rice) for comparison with in situ data. The model validation was run for the 2005-2012 period.

Table 4: Variables of Input and Parameters (Calibrated)

\begin{tabular}{cccccc}
\hline Input & Unit & Rice & Grass & Shrub & Forest \\
\hline$\Theta_{\text {sat } 1}$ & $\mathrm{~m}^{3} \mathrm{~m}^{-3}$ & 0.36 & 0.42 & 0.36 & 0.40 \\
\hline$\Theta_{\text {sat } 2}$ & $\mathrm{~m}^{3} \mathrm{~m}^{-3}$ & 0.40 & 0.40 & 0.40 & 0.65 \\
\hline$K_{\text {sat } 1}$ & $\mathrm{~m} \mathrm{~d}^{-1}$ & 0.01 & 0.01 & 0.03 & 0.15 \\
\hline$K_{\text {sat } 2}$ & $\mathrm{~m} \mathrm{~d}^{-1}$ & 0.03 & 0.03 & 0.03 & 0.45 \\
\hline$c$ & $\mathrm{~d}^{-1}$ & 0.25 & 0.25 & 0.25 & 0.25 \\
\hline$D_{e}$ & $\mathrm{~m}$ & 0.15 & 0.15 & 0.15 & 0.15 \\
\hline$L A I_{\max }$ & $\mathrm{m}^{2} \mathrm{~m}^{-2}$ & 2.50 & 2.50 & 4.50 & 6.00 \\
\hline$H_{\max }$ & $\mathrm{m}$ & 0.80 & 0.40 & 2.50 & 10.0 \\
\hline$R D_{\max }$ & $\mathrm{m}$ & 0.60 & 0.50 & 1.20 & 2.50 \\
\hline$\mu$ & - & 0.45 & 0.40 & 0.30 & 0.75 \\
\hline$K_{\text {cb ini }}$ & - & 1.05 & 0.40 & 0.50 & 0.40 \\
\hline$K_{\text {cb mid }}$ & - & 1.20 & 0.90 & 0.95 & 1.50 \\
\hline$K_{\text {cb end }}$ & - & 0.90 & 0.70 & 0.75 & 0.7 \\
\hline$p$ & - & 0.55 & 0.55 & 0.50 & 0.65 \\
\hline$C N_{2}$ & - & 75 & 60 & 65 & 50 \\
\hline & & & & &
\end{tabular}

Both the models simulated the ET values from 2001 to 2012 and the model performances were examined by calculating the coefficient of determination $\left(R^{2}\right)$ and Nash-Sutcliffe efficiency (NSE) [46]. We used a simple averaging method (to average ET from all crops appearing in the HRU 3) to calculate the mean BEACH ET for HRU 3 and then compared it with SWAT and MODIS ET (used zonal statistics) for this HRU.

\subsection{MODIS Evapotranspiration}

Monthly MODIS ET datasets with 1-km spatial resolution generated based on the MOD16 algorithm in [32] from 2001 to 2012 was used to extract actual ET. These ET was verified by comparing with measured data of both globally and locally at 46 eddy flux towers presented in the study of Mu et al. [32]. We developed a simple model in the ModelBuilder of ArcMap-Arclnfo to extract the monthly and yearly ET using ArcGIS functions as in the Figure 3. 


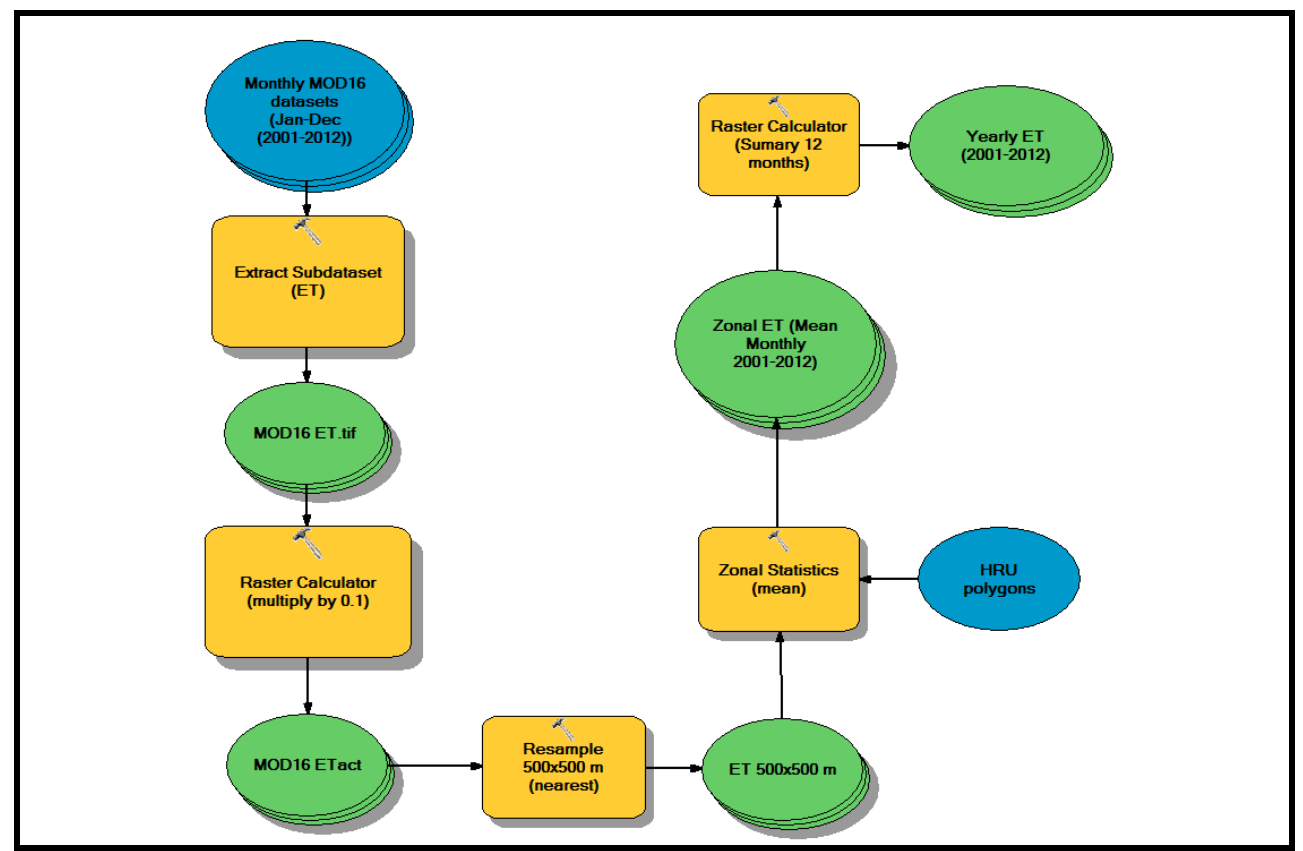

Figure 3: Model Flow Work for Monthly and Yearly ET Calculation using MODIS Datasets; wherein, the Blue Ellipses are the Model's Inputs, The Yellow Rounded Rectangles Perform the Model's Functions and the Green Ellipses are the Temporal and Final Outputs

\section{Results and Discussion}

\subsection{SWAT Calibration and Validation for Surface Runoff}

Overestimates of before calibrated discharge values (computing from $1^{\text {st }}$ January 2001 to $31^{\text {st }}$ December 2005) compared to gauged data (more triangles above the red linear and value of $Y$ axis larger than $X$ axis as well) have been shown on the Figure $4 a$ and the R2 and NSE were assumed to be low, 0.58 and -0.4 respectively. However, after adjusting the model parameters (mentioned in the method section) the model simulated $Q$ (after calibration) matched the stream-gauged information (NSE $=0.62$ and $R^{2}=0.80$ ) well.

Figure $4 \mathrm{~b}$ shows the good agreement between SWAT simulated and observed discharge values in the validated stage performing from $1^{\text {st }}$ June 2001 to $31^{\text {st }}$ December 2012 with R2 of 0.88 and NSE of 0.65. Although there were still some over/underestimates of river discharge at some peaks, the result of model calibration and validation revealed the important capability of SWAT to produce the $Q$ matching closely to measured data in a medium-size tropical watershed (SWAT was developed for arid/semi-arid river catchments). In addition, this point was supported by some similar previous studies of $[19,22,23]$ even for a case study in Vietnam [24]. 


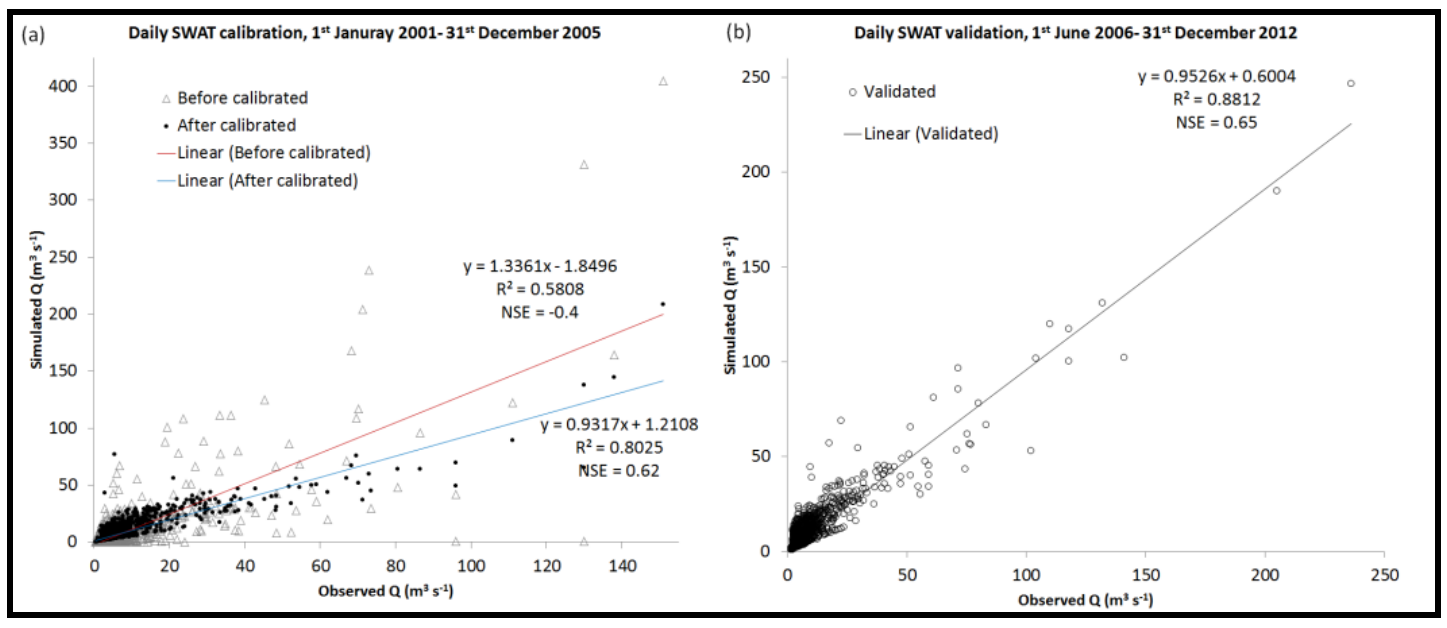

Figure 4: Scatted Plots of SWAT Calibration (a) and Validation (b) for Runoff

\subsection{BEACH Calibration and Validation for Evaporation}

The BEACH started calibrating for a 2001-2004 period for four types of crops (mentioned in Table 4) and the before-calibrated simulated $E$ (averaged from rice and shrub $E$ ) was much lower compared to observed $E$ (Figure $5 a, R^{2}=0.23$ and NSE $=-0.22$ ). Especially in some periods such as in December 2001 and 2003 the simulated $E$ was a large uncertainty but after consideration of the sowing dates of the rice crop (December is the irrigation time of the winter-spring season) we adjusted the rice sowing and harvesting dates and increased the $K_{c}$ and a good agreement was found after calibration (Figure $5 b)$ with $R^{2}$ of 0.76 and NSE of 0.62 , except for some underestimates of some peaks. For the daily simulation, these values of $R^{2}$ and NSE are asserted at a good level and also certified by $[47,48]$.

Model validation was done for an eight-year period from 2005 to 2015 and the result was illustrated on the Figure $5 \mathrm{c}$ with acceptable agreement between calculated $E$ and field measured $E\left(R^{2}=0.71\right.$ and NSE $=0.65)$. Furthermore, the figure indicated the variations $(0.1$ to $12 \mathrm{~mm})$ of $E$ values in the validated period. In general, the $\mathrm{E}$ values were highest from March to May and lower from June to September. Besides the climatic aspects such as humidity, wind, radiation and precipitation, the cropping irrigation, crop growing [30] and land use changes [4] have important effects on E and ET. For this case study, some differences between simulated and observed $E$ might come from changes in crop and land use because we kept the cropping sowing dates and land use unchanged over the simulation period. To improve the model performance, an updated crop type and time might be needed, however for long-term observation it is very time consuming.

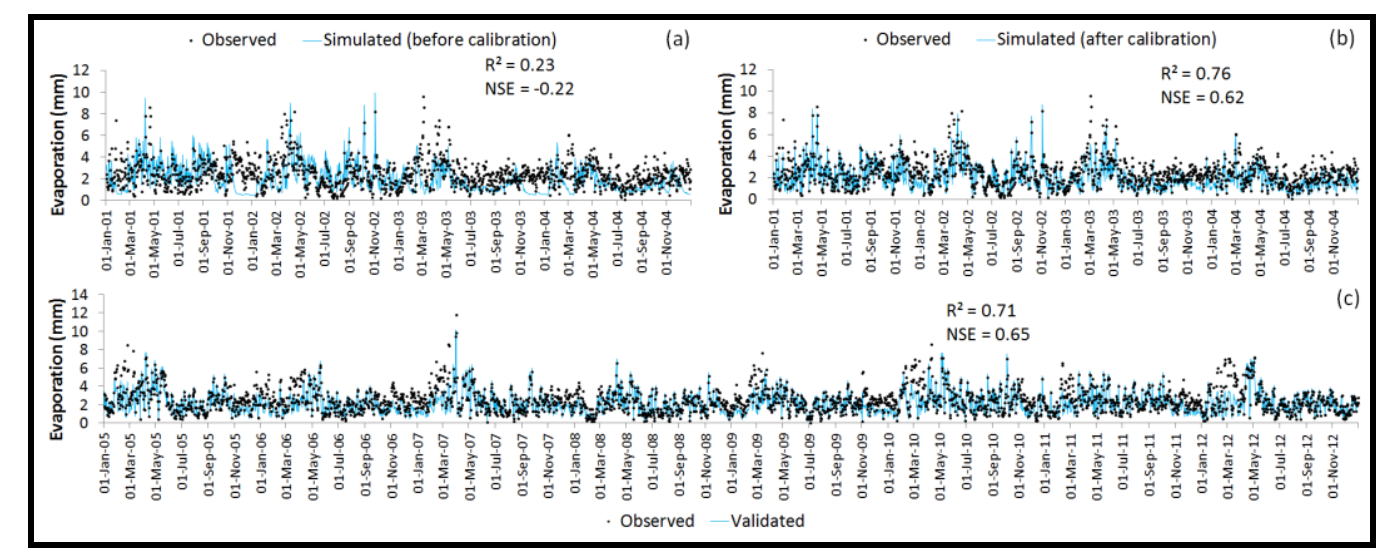

Figure 5: Daily Before (a) After (b) Calibrated and Validated (c) Evaporation Compared to Measured Evaporation 


\subsection{Comparing SWAT and BEACH Daily ET (of HRU3 from 2001 to 2012)}

The time series daily actual evapotranspiration values calculated by SWAT (for HRUs) and BEACH (averaged from the four crop's ET) and measured rainfall were presented and compared to each other by the line graph (Figure 6). The graph indicated not only the variations of ET (0.3 to $14 \mathrm{~mm} \mathrm{day}^{-1}$ ) and rainfall but also the yearly routine of ET. The ET values appeared very high before rainy seasons (May to August) and lowest in winter (December to March). The changing in ET is basically related to stand density (number of trees per hectare) and also incoming solar radiation (referring to season) [49]. A better understanding of the ET routine and trends might help to predict the ET in the future but a longer time of simulation is needed (instead of 12 years). There were two periods May to September 2003 and 2004 with large differences in ETs estimated by SWAT and BEACH. Unfortunately, without the in situ measured ETs for comparison we did not know whether the SWAT ET was more accurate than the BEACH ET or the reverse. However, based on the good relationship between BEACH E and observed $E$ (discussed in section $4 \mathrm{~b}$ ) the BEACH ET (lower value) would be more reliable in these computational times.

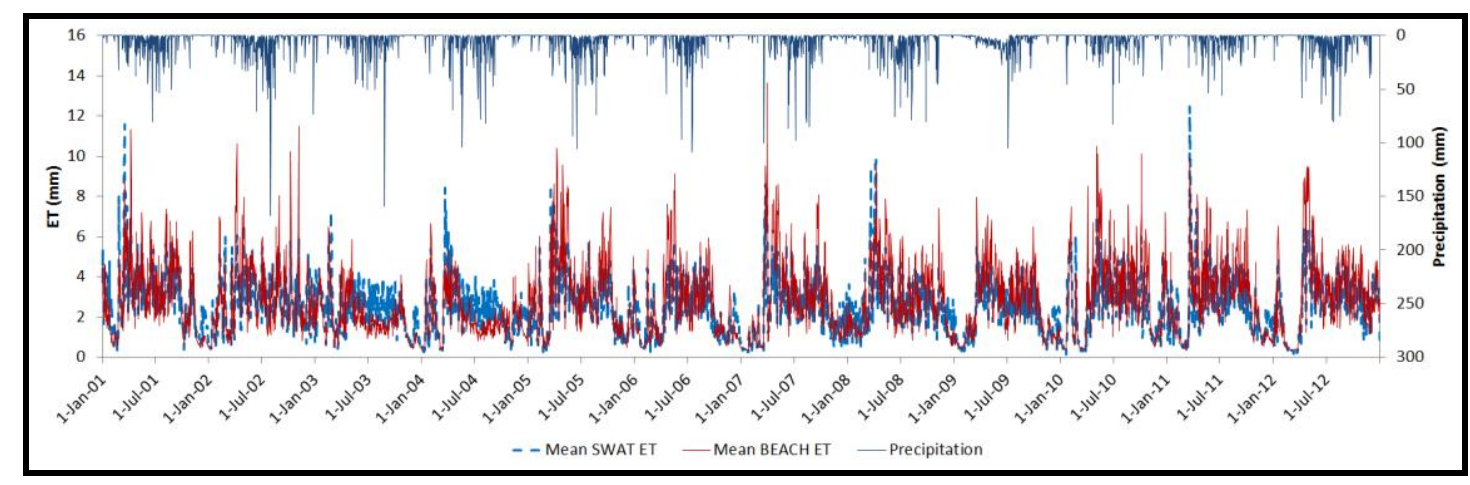

Figure 6: Line Graph of Time Series SWAT and BEACH ET (Calculated for HRU 3) and Measured Rainfall

We analyzed the relationship between the two estimates of ET represented in the Figure 7 with the moderate correlation $\left(R^{2}\right.$ of 0.73$)$. However, both models predicted ETs closely together when the rates were low $(<4 \mathrm{~mm})$. These rates consisted of more than $90 \%$ of the estimates. The interesting correlation between measured daily rainfall and SWAT ET was also indicated on the figure. Basically, the wet days (with precipitation $>0 \mathrm{~mm}$ day $^{-1}$ ) had ET rates from one to four $\mathrm{mm}$ day $^{-1}$. On the other hand, all the ET values are higher than six $\mathrm{mm}$ day $^{-1}$ generated in dry day (no rainfall). The ET of 0.3 to one $\mathrm{mm}$ day $^{-1}$ and rainfall less than $10 \mathrm{~mm}$ day $^{-1}$ were calculated for the winter time. This relationship could provide helpful information for cropping irrigation [35], the drought season [50], particularly when we could forecast the ET values [51], and for improved understanding of the interactions between land surfaces and the atmosphere [31, 52]. 


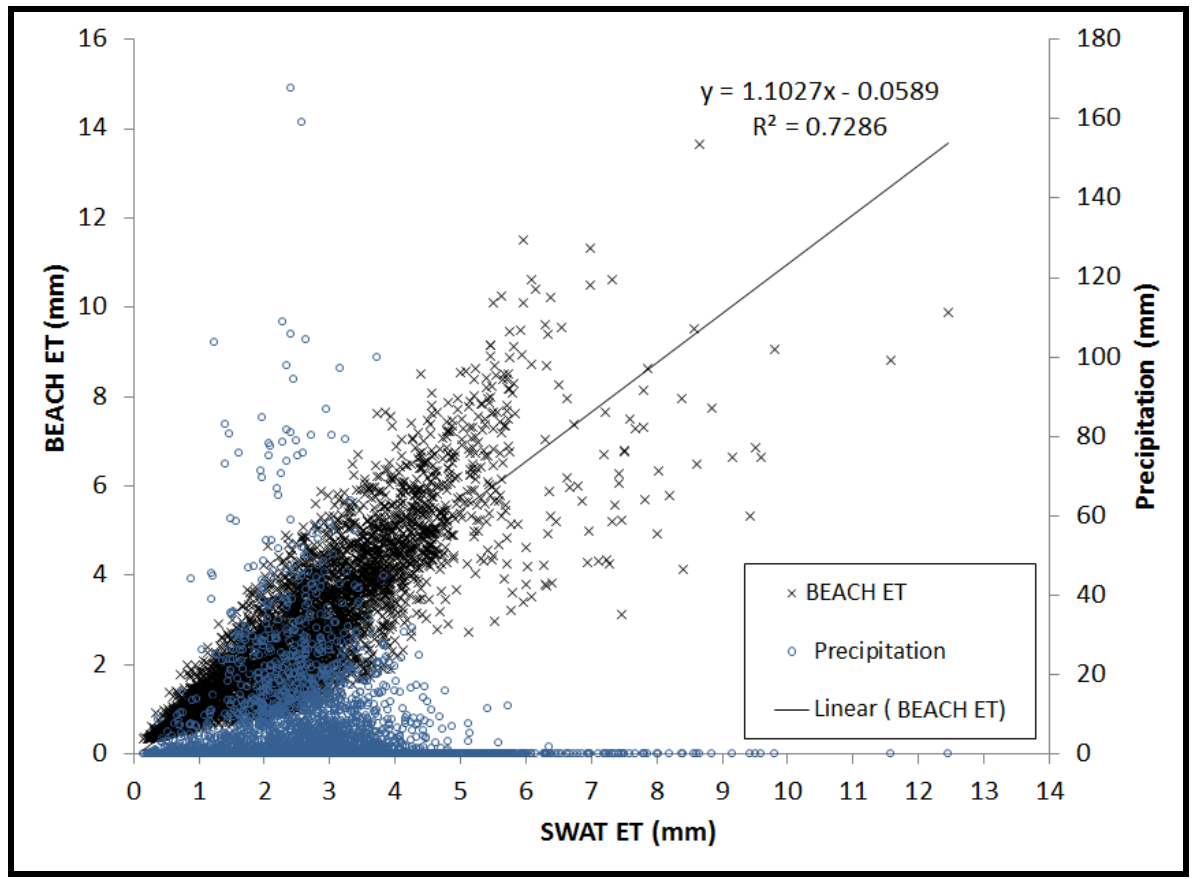

Figure 7: Relationship between Daily SWAT and BEACH ET, SWAT ET and Rainfall

\subsection{Comparing SWAT and BEACH (CN) Daily Runoff (2001-2012)}

Figure 8 shows the daily discharge values generated by the SWAT and BEACH models from 2001 to 2012 compared with the daily measured data at the watershed outlet. There were some peaks of discharge captured by the models, varying from 100 to $240 \mathrm{~m}^{3} \mathrm{~s}^{-1}$ and most values ranged from 0 to 50 $\mathrm{m}^{3} \mathrm{~s}^{-1}$. The SWAT appeared to predict the discharge closer to observed information than the BEACH with NSE of 0.67 and 0.61 for the models respectively. Generally, both models slightly underestimated the discharge. However, close relationships between simulated and field measured discharge can be seen in the figure in both cases with $\mathrm{R}^{2}$ of 0.81 for the SWAT and 0.83 for the BEACH.

Although the two models use the same $\mathrm{CN}$ method [53] to simulate the discharge value, many reasons could be explained for the differences of $Q$ values shown in the Figure 8 such as the difference in model structure, in inputs etc. Many previous studies found that the modeled runoff is sensitive to $\mathrm{CN}$ values $[19,54,55]$ we altered the CN value of each land use of each class (of crops for the case of he $\mathrm{BEACH}$ ) in oder to calculate to discharge close to the observed data. 


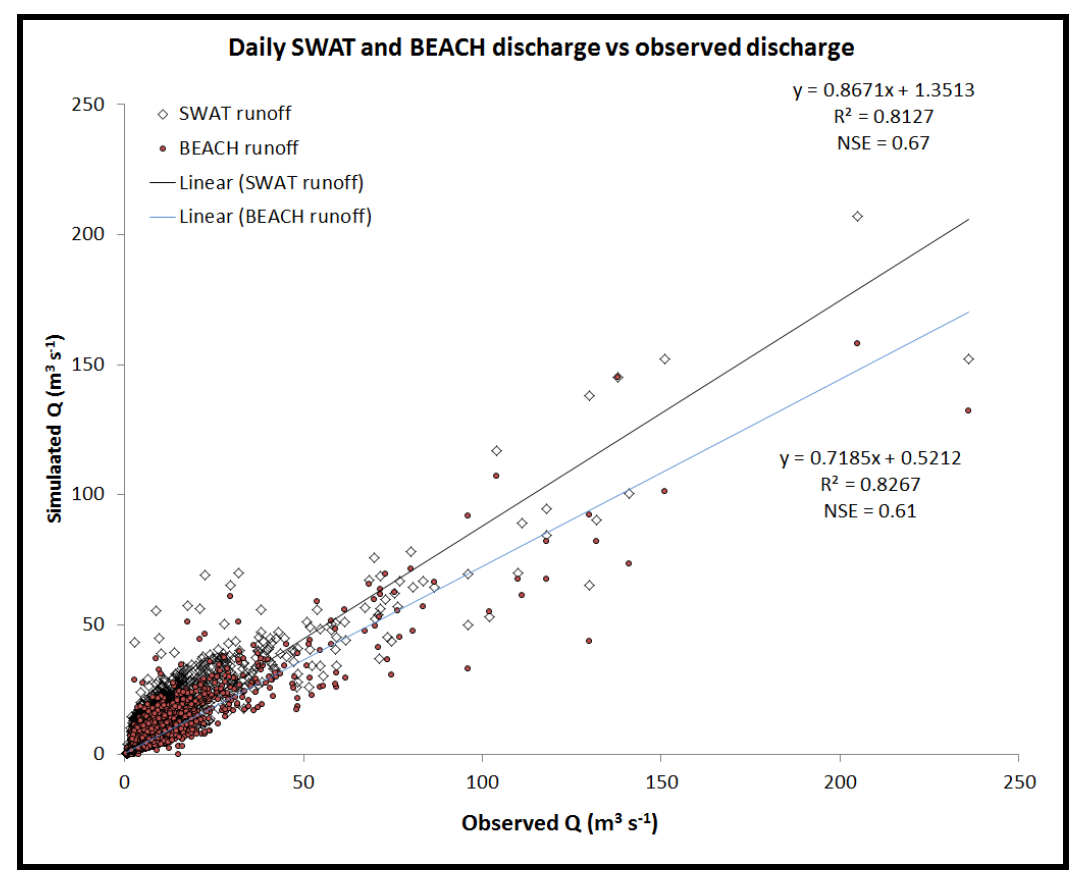

Figure 8: Relationship between Daily SWAT, BEACH and Observed Discharge from 2001 to 2012

\subsection{Monthly SWAT and BEACH vs. MODIS ET of HRU 3 from 2001-2012}

The variations of monthly ET calculated from MODIS scenes, from SWAT and BEACH models and their standard deviations from 2001 to 2012 are presented in the bar graph of Figure 9. Although the ET from all estimates was highest from May to October and lowest from December to February, the MODIS ET varied gradually over the twelve years. Both the SWAT and BEACH estimated the ET in 2003 and 2004 much lower than the MODIS ET. The MODIS ET was estimated higher than the BEACH ET and the SWAT ET was lowest in general. The standard deviations of the three ET sources calculated for each month fluctuated from three to $40 \mathrm{~mm}$ and the average value was $17.5 \mathrm{~mm}$. The MODIS ET was estimated using the improved ET algorithm at global scale (global parameters) [32] and compared to the watershed scale in this study we assert that the agreement between the three estimated ETs was at a good level.

The monthly ET varied over different seasons and the most driving factors on ET found in the study of [11] were relative humidity and wind speed at two meters high. Both the SWAT and BEACH models thoroughly take into account these two factors but the algorithm for MODIS ET does not include wind speed and topographic influences (elevation, slope and aspect) [33].

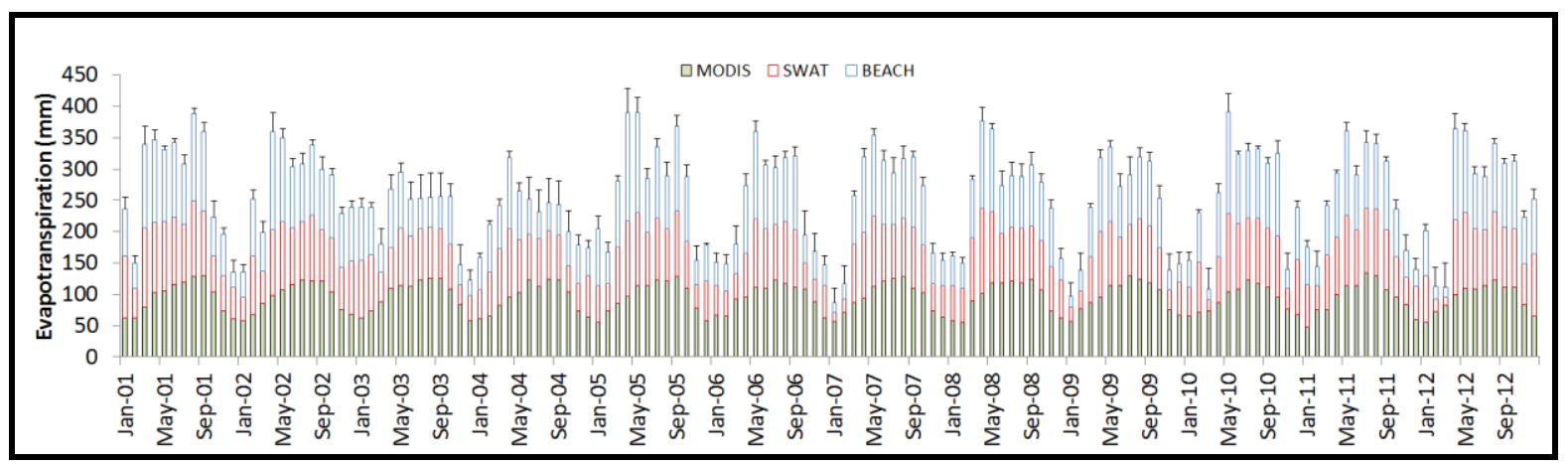

Figure 9: Monthly ET Extracted from MODIS Product \& Estimated by SWAT \& BEACH Models in 2001-2012 Period 


\subsection{ET Trend Analyses}

The slightly downward trend of ET in the 2001-2012 periods has been shown in the Figure 10 for all cases of estimations illustrated by the negative slope line of the equations. However, in the first four years the ET decreased gradually but in the rest of the years the rates were more stable. While all data sources represented the decrease of monthly ET, the 12 years of simulation might be too short to come to a conclusion that the annual ET in the study region is currently declining and will in the future. Therefore, longer term assessment could be needed (40 years or more) and the reasons for this trend were also out of this paper's scope.

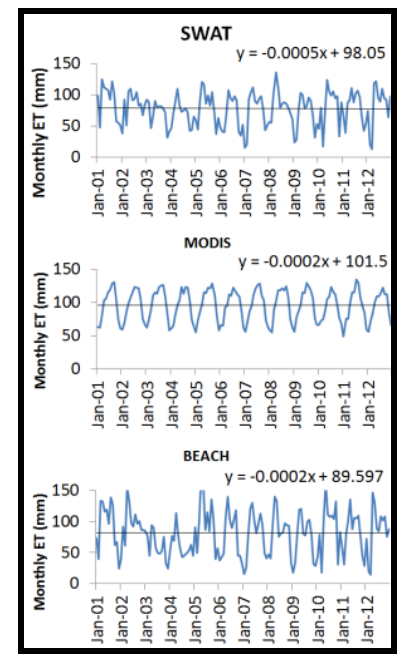

Figure 10: SWAT, BEACH and MODIS ET Trends

\subsection{SWAT and MODIS ET Spatial Distributions}

The yearly ET accumulations of the SWAT and BEACH were mapped for twenty HRUs (1-20) of the Nam Kim watershed with two-year intervals from 2002 to 2012 (Figure 11). Crossed comparison can be made between the maps of SWAT ET, MODIS ET and between SWAT and MODIS ET maps. Among the SWAT ET maps, the 2004 one had the highest ET rate of 1069 to $1086 \mathrm{~mm}_{\text {year }}{ }^{-1}\left(\mathrm{~mm} \mathrm{y}^{-1}\right)$ flowing by 2008, 2002, 2012, 20010 and 2006 had the lowest rate ranging from 751 to $773 \mathrm{~mm} \mathrm{y}^{-1}$. Among the MODIS maps, the map 2006 had the highest rate of 1050 to $1192 \mathrm{~mm} \mathrm{y}^{-1}$ flowing by 2004, 2002, 2012, 2008 and 2010 had the lowest rate of 950 to $1150 \mathrm{~mm} \mathrm{y}^{-1}$. In general, the MODIS maps had higher ET rates than SWAT maps. The yearly ET calculated for the HRUs also varied over time in all the maps. Some similarities in the maps can be seen in the HRUs such as HRU 7, 8, 10, 13, 14 and 20 (except the year 2004) with lower ET and 1, 5, 11 and 19 with higher ET. Differences between SWAT and MODIS distributed ET appeared in the figure as well, for example the HRU 12, 16 and 14 with lower ET in MODIS maps and higher ET in the SWAT ones. These dissimilarities were thought to be normal because the results were estimated from different approaches and scales. However, the agreements were dominant.

The changes of ET patterns might be related to changes in land use land cover for example the decrease in canopy interception causes a decrease in ET and percolation and increase in runoff [4, 56]. In addition, as discussed in the section $4 \mathrm{f}$ that SWAT used distributed soil and topographic inputs, therefore the SWAT ET might be more precise than MODIS due to the fact that global satellite products generally contain noises [34]. 


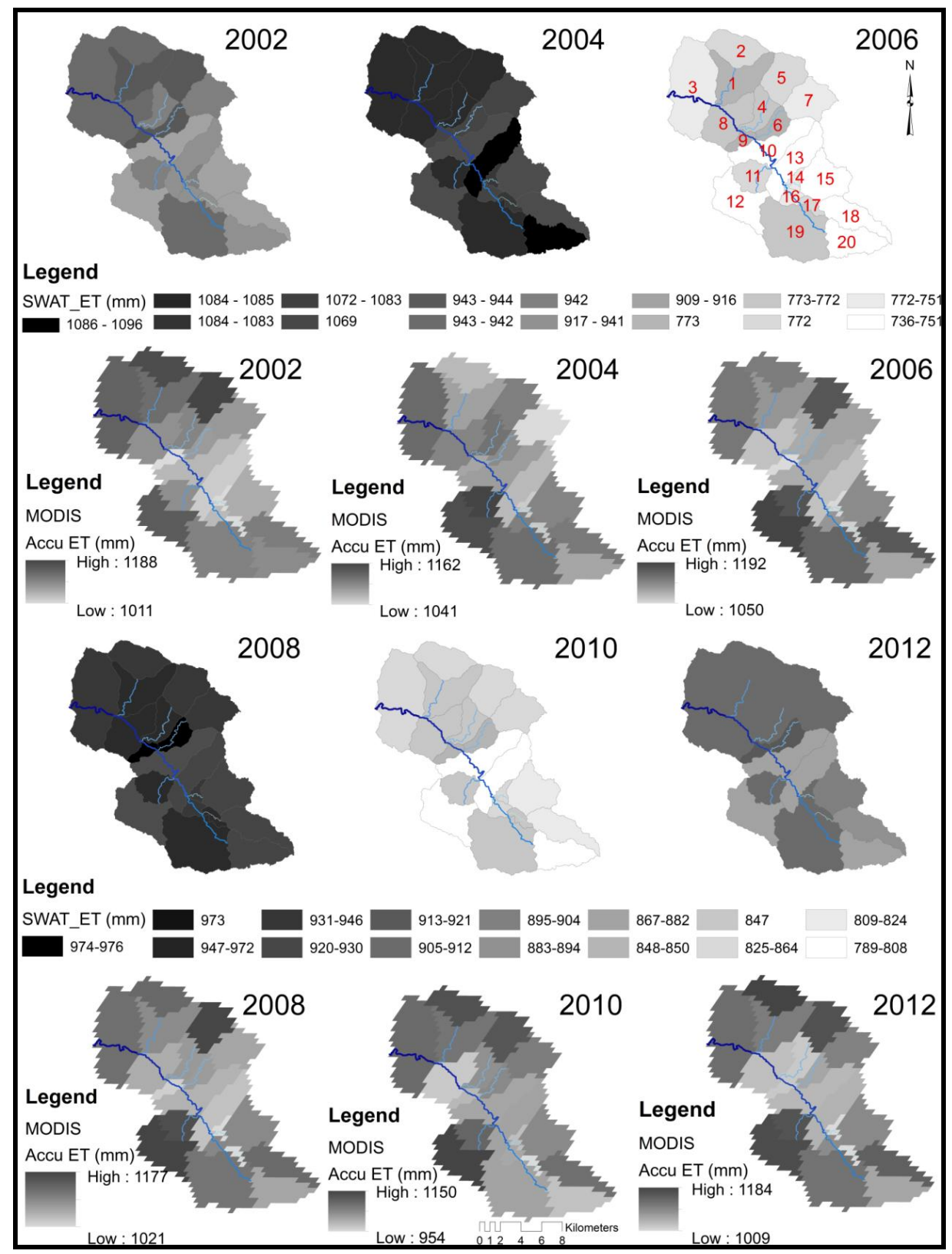

Figure 11: Yearly Spatial ET Distribution Modeled by SWAT and Derived from MODIS Products (Accu Stands for Accumulative, the MODIS Maps were Results of the Model, Figure 3, built in ArcMap Discussed in the Method Section)

\section{Summary and Conclusions}

Daily discharge and evaporation were calculated and validated by SWAT for the $268 \mathrm{~km}^{2}$ watershed in the tropical region in North Vietnam with acceptable agreement between simulated and observed data verified by the NSE and $R^{2}$ values. This might reveal a possible application of the two hydrological models for tropical regions. The good correlations between discharges produced by the models were also represented in the study results as well.

Although the daily estimated ETs by the SWAT and BEACH models were not validated, they matched well with each other and the monthly ETs were compared with the published MODIS product. Despite the SWAT and BEACH ETs being slightly lower than the MODIS ET, basically a close correlation 
between them can be seen in the study results (analyzed using standard deviations) and also all the monthly ETs showed the slight downward trend in the simulation time (2001-2012).

The results of zonal statistics applied for the yearly MODIS and SWAT ETs were mapped, providing interesting information of temporal and distributed ET patterns in the watershed. Both differences and similarities could be found in the map but the correspondence between them was dominant. We conclude that the MODIS ET was very helpful for verifying the smaller scale of ET estimation by the two models.

\section{Acknowledgements}

Authors acknowledge the Vietnamese National Center for Hydro-Meteorological Forecasting, the Vietnamese Environment and Resources Corporation for providing meteorological and topographical data for this research and the Numerical Terradynamic Simulation Group (NTSG) at the University of Montana for providing the MOD16 ET data. We also thank the anonymous reviewers for their valuable comments.

\section{References}

[1] Lopez-Vicente, M., et al. Predicting Runoff and Sediment Connectivity and Soil Erosion by Water for Different Land Use Scenarios in the Spanish Pre-Pyrenees. CATENA. 2013. 102; 62-73.

[2] Liu, M., et al. Effects of Multiple Environment Stresses on Evapotranspiration and Runoff Over Eastern China. Journal of Hydrology. 2012. 426-427; 39-54.

[3] Camporese, M., et al. Simplified Modeling of Catchment-Scale Evapotranspiration via Boundary Condition Switching. Advances in Water Resources. 2014. 69; 95-105.

[4] Dias, L.C.P., et al. Effects of Land Cover Change on Evapotranspiration and Streamflow of Small Catchments in the Upper Xingu River Basin, Central Brazil. Journal of Hydrology: Regional Studies. 2015. 4, Part B; 108-122.

[5] Boegh, E., et al. Remote Sensing Based Evapotranspiration and Runoff Modeling of Agricultural, Forest and Urban Flux Sites in Denmark: From Field to Macro-Scale. Journal of Hydrology. 2009. 377 (3-4) 300-316.

[6] Lenzi, M.A. and DiLuzio, M. Surface Runoff, Soil Erosion and Water Quality Modelling in the Alpone Watershed using AGNPS Integrated with a Geographic Information System. European Journal of Agronomy. 1997. 6 (1-2) 1-14.

[7] Marttila, H. and Klove, B. Managing Runoff, Water Quality and Erosion in Peatland Forestry by Peak Runoff Control. Ecological Engineering. 2010. 36 (7) 900-911.

[8] Mchunu, C. and Chaplot, V. Land Degradation Impact on Soil Carbon Losses through Water Erosion and CO2 Emissions. Geoderma. 2012. 177; 72-79.

[9] Tripathi, R., et al. Climate Change, Urban Development, and Community Perception of an Extreme Flood: A Case Study of Vernonia, Oregon, USA. Applied Geography. 2014. 46 (0) 137-146.

[10] Rogger, M., et al. Runoff Models and Flood Frequency Statistics for Design Flood Estimation in Austria - Do they Tell a Consistent Story? Journal of Hydrology. 2012. 456-457 (0) 30-43. 
[11] Petković, D., et al. Determination of the Most Influential Weather Parameters on Reference Evapotranspiration by Adaptive Neuro-Fuzzy Methodology. Computers and Electronics in Agriculture. 2015. 114; 277-284.

[12] Sun, J., Salvucci, G.D. and Entekhabi, D. Estimates of Evapotranspiration from MODIS and AMSR-E Land Surface Temperature and Moisture Over the Southern Great Plains. Remote Sensing of Environment. 2012. 127; 44-59.

[13] Almorox, J., Quej, V.H. and Martí, P. Global Performance Ranking of Temperature-Based Approaches for Evapotranspiration Estimation Considering Köppen Climate Classes. Journal of Hydrology. 2015. 528; 514-522.

[14] Horton, R.E. The Role of Infiltration in the Hydrologic Cycle. Eos Trans. AGU. 1933. 14; 446-460.

[15] Sawano, S., et al. Development of a Simple Forest Evapotranspiration Model Using a ProcessOriented Model as a Reference to Parameterize Data from a Wide Range of Environmental Conditions. Ecological Modelling. 2015. 309-310; 93-109.

[16] Kisi, O., et al. Long-Term Monthly Evapotranspiration Modeling by Several Data-Driven Methods Without Climatic Data. Computers and Electronics in Agriculture. 2015. 115; 66-77.

[17] Velpuri, N.M., et al. A Comprehensive Evaluation of Two MODIS Evapotranspiration Products Over the Conterminous United States: Using Point and Gridded FLUXNET and Water Balance ET. Remote Sensing of Environment. 2013. 139; 35-49.

[18] Guber, A.K., et al. Modeling Runoff and Microbial Overland Transport With KINEROS2/STWIR Model: Accuracy and Uncertainty as Affected by Source of Infiltration Parameters. Journal of Hydrology. 2014. 519 Part A (0) 644-655.

[19] Tibebe, D.B., W. Surface Runoff and Soil Erosion Estimation Using the Swat Model in the Keleta Watershed, Ethiopia. Land Degradation \& Development. 2011. 22 (6) 551-564.

[20] Casali, J., et al. Runoff, Erosion, and Water Quality of Agricultural Watersheds in Central Navarre (Spain). Agricultural Water Management. 2008. 95 (10) 1111-1128.

[21] Linde, A.H.t., et al., Comparing Model Performance of Two Rainfall-Runoff Models in the Rhine Basin using Different Atmospheric Forcing Data Sets. Hydrol. Earth Syst. Sci., 12, 943-957, 2008, 2008.

[22] Fukunaga, D.C., et al. Application of the SWAT Hydrologic Model to a Tropical Watershed at Brazil. CATENA. 2015. 125 (0) 206-213.

[23] Ndomba, P., Mtalo, F. and Killingtveit, A. SWAT Model Application in a Data Scarce Tropical Complex Catchment in Tanzania. Physics and Chemistry of the Earth, Parts A/B/C. 2008. 33 (813) 626-632.

[24] Vu, M.T., Raghavan, S.V. and Liong S.Y. SWAT Use of Gridded Observations for Simulating Runoff - A Vietnam River Basin Study. Hydrology and Earth System Sciences. 2012. 16 (8) 28012811.

[25] Howell, T.A., et al. Evapotranspiration, Water Productivity and Crop Coefficients for Irrigated Sunflower in the U.S. Southern High Plains. Agricultural Water Management. 2015. 162; 33-46. 
[26] Connan, O., et al. In Situ Measurements of Tritium Evapotranspiration (3H-ET) Flux Over Grass and Soil Using the Gradient and Eddy Covariance Experimental Methods and the FAO-56 Model. Journal of Environmental Radioactivity. 2015. 148; 1-9.

[27] Consoli, S. and Vanella, D. Comparisons of Satellite-Based Models for Estimating Evapotranspiration Fluxes. Journal of Hydrology. 2014. 513; 475-489.

[28] Tian, F., et al. Estimation of Evapotranspiration and its Partition Based on an Extended ThreeTemperature Model and MODIS Products. Journal of Hydrology. 2013. 498; 210-220.

[29] Sun, Z., et al. Development of a Simple Remote Sensing EvapoTranspiration Model (SimReSET): Algorithm and Model Test. Journal of Hydrology. 2009. 376 (3-4) 476-485.

[30] Jaksa, W.T. and Sridhar, V. Effect of Irrigation in Simulating Long-Term Evapotranspiration Climatology in a Human-Dominated River Basin System. Agricultural and Forest Meteorology. 2015. 200; 109-118.

[31] Mu, Q., et al. Development of a Global Evapotranspiration Algorithm Based on MODIS and Global Meteorology Data. Remote Sensing of Environment. 2007a. 111; 519-536.

[32] Mu, Q., Zhao, M. and Running, S.W. Improvements to a MODIS Global Terrestrial Evapotranspiration Algorithm. Remote Sensing of Environment. 2011.115 (8) 1781-1800.

[33] Hu, G., Jia, L. and Menenti, M. Comparison of MOD16 and LSA-SAF MSG Evapotranspiration Products Over Europe for 2011. Remote Sensing of Environment. 2015. 156; 510-526.

[34] Westerhoff, R.S. Using Uncertainty of Penman and Penman-Monteith Methods in Combined Satellite and Ground-Based Evapotranspiration Estimates. Remote Sensing of Environment. 2015. 169; 102-112.

[35] Immerzeel, W.W. and P. Droogers. Calibration of a Distributed Hydrological Model Based on Satellite Evapotranspiration. Journal of Hydrology. 2008. 349 (3-4) 411-424.

[36] Nguyen Van Tai, et al. Vietnam Assessment Report on Climate Change Institute of Strategy and Policy on natural resources and environment, 2009. Viet Nam Van hoa - Thong tin Publishing House: 318-2009/CXB/16-28/VHTT; 112-115.

[37] Neitsch, S.L., et al., 2009: Soil and Water Assessment Tool Theoretical Documentation, Version 2009. Texas Water Resources Institute Technical Report No. 406.

[38] USDA-SCS, USDA Soil Conservation Service-National Engineering Handbook Section 4. Hydrology and, 1972. Chapters 4-10.

[39] Green, W.H.a.G.A. 1911: Studies of Soil Physics, Part I - The Flow of Air and Water through Soils. Physical Hydrology for Ecosystems.

[40] Ritchie, J.T. A Model for Predicting Evaporation from a Row Crop with Incomplete Cover. Water Resour. Res. 1972. 8; 1204-1213.

[41] Hargreaves, G.L., et al., Agricultural Benefits for Senegal River Basin. Engr. 1985. 111 (2) 113124. 
[42] Priestley, C.H.B. and Taylor, R.J. On the Assessment of Surface Heat Flux and Evaporation Using Large-Scale Parameters. Mon. Weather Rev. 1972. 100; 81-92.

[43] Monteith, J.L. Evaporation and the Environment. In: The State and Movement of Water in Living Organisms. 19th Symposia of the Society for Experimental Biology. Cambridge Univ. Press, London, U.K. 1965. 205-234.

[44] Sheikh, V., Visser, S. and Stroosnijder, L. A Simple Model to Predict Soil Moisture: Bridging Event and Continuous Hydrological (BEACH) Modelling. Environmental Modelling \& Software. 2009. 24 (4) 542-556.

[45] Allen, R.G., et al., 1998: Crop Evapotranspiration: Guidelines for Computing Cropwater Requirements. In: Irrigation and Drainage. Paper 56. FAO, Rome.

[46] Nash, J.E. and Sutcliffe, J.V. River Flow Forecasting through Conceptual Models 1: A Discussion of Principles. Journal of Hydrology. 1970. 10 (3) 282-290.

[47] Moriasi, D.N., et al. Model Evaluation Guidelines for Systematic Quantification of Accuracy in Watershed Simulations. Am. Soc. Agric. Biol. Eng. 2007.50 (3) 885-900.

[48] Santhi, C., et al. Validation of the SWAT Model on a Large River Basin with Point and Nonpoint Sources. J. Am. Water Resour. Assoc. 2001.37 (5) 1169-1188.

[49] Vanderhoof, M.K. and Williams, C.A. Persistence of MODIS Evapotranspiration Impacts from Mountain Pine Beetle Outbreaks in Lodgepole Pine Forests, South-Central Rocky Mountains. Agricultural and Forest Meteorology. 2015. 200; 78-91.

[50] Vicente-Serrano, S.M., et al. Contribution of Precipitation and Reference Evapotranspiration to Drought Indices under Different Climates. Journal of Hydrology. 2015. 526; 42-54.

[51] Ballesteros, R., Ortega, J.F. and Moreno, M.Á. FORETo: New Software for Reference Evapotranspiration Forecasting. Journal of Arid Environments. 2016. 124; 128-141.

[52] Hong, S.H., Hendrickx, J.M.H. and Borchers, B. Up-Scaling of SEBAL Derived Evapotranspiration Maps from Landsat $(30 \mathrm{~m})$ to MODIS $(250 \mathrm{~m})$ Scale. Journal of Hydrology. 2009. $370(1-4)$ 122138.

[53] USDA-SCS, Technical Release 55, Urban Hydrology for Small Watersheds. United States Department of Agriculture, Soil Conservation Service, 1986.

http://www.wcc.nrcs.usda.gov/hydro//hydro-tools-models-tr55.html.(Chapter 9 and 10).

[54] Jaswinder Singh, Vernon Knapp, H. and Demissie, M. Hydrologic Modeling of the Iroquois River Watershed Using HSPF and SWAT. Watershed Science Section Illinois State Water Survey. 2004.

[55] Shen, Z.Y., et al. A Comparison of WEPP and SWAT for Modeling Soil Erosion of the Zhangjiachong Watershed in the Three Gorges Reservoir Area. Agricultural Water Management. 2009. 96 (10) 1435-1442.

[56] Lin, B., et al. Analyses of Landuse Change Impacts on Catchment Runoff Using Different Time Indicators Based on SWAT Model. Ecological Indicators. 2015. 58; 55-63. 